\title{
Olive oil characteristics of eleven cultivars produced in a high-density grove in Valladolid province (Spain)
}

\author{
Nuno Rodrigues ${ }^{1} \cdot$ Susana Casal ${ }^{2} \cdot$ Teresa Pinho $^{2} \cdot$ Rebeca Cruz $^{2} \cdot$ Paula Baptista $^{1} \cdot$ Hugo Martín $^{3}$. \\ M. Cármen Asensio-S.-Manzanera ${ }^{3} \cdot$ António M. Peres $^{1} \cdot$ José Alberto Pereira ${ }^{1} \mathbb{C}$
}

Received: 10 July 2021 / Revised: 22 August 2021 / Accepted: 27 August 2021 / Published online: 24 September 2021

(c) The Author(s), under exclusive licence to Springer-Verlag GmbH Germany, part of Springer Nature 2021

\begin{abstract}
The olive oil composition of eleven cultivars (cvs. Arbequina, Arbosana, Arroniz, Cornicabra, Frantoio, Hojiblanca, Manzanilla, Picual, Picudo, Redondilla and Royuela) cultivated in a high-density olive grove located in a non-traditional producing region (Valladolid, Spain) was studied during four consecutive crop seasons. The results showed that the 122 monovarietal olive oils studied could be classified as extra virgin oils, according to the quality parameters. Furthermore, the olive cultivar had a marked effect on the chemical composition and antioxidant activity. In general, olive oils from cvs. Picual and Cornicabra showed the highest total phenolic contents, oxidative stability, and tocopherols contents, whereas the worst results for oxidative stability were observed for cv. Redondilla olive oils, probably associated to the lowest contents of phenolics and tocopherols and the highest amounts of polyunsaturated fatty acids. Finally, it was found that, despite the different crop years evaluated, the quality-chemical profiles could be used to successfully discriminate the monovarietal oils under study (linear discriminant analysis sensitivities: $92 \pm 5 \%$ for the repeated K-fold cross-validation), using the data of 15 non-redundant variables identified by the simulated annealing variable selection algorithm.
\end{abstract}

Keywords Monovarietal olive oils · Quality parameters · Chemical composition · Oxidative stability · Cultivar discrimination

\section{Introduction}

Olive (Olea europaea L.) is one of the fastest-growing crops worldwide, mainly due to the increased popularity and consumption of olive oil worldwide, its appreciated sensory characteristics and the recognized positive effect of its consumption on humans health.

Traditionally, this crop is associated with countries of the Mediterranean basin, representing more than $90 \%$ of the world area occupied by this crop, being Spain the first world

José Alberto Pereira

jpereira@ipb.pt

1 Centro de Investigação de Montanha (CIMO), Instituto Politécnico de Bragança, Campus de Santa Apolónia, 5300-253 Bragança, Portugal

2 LAQV/REQUIMTE, Laboratory of Bromatology and Hydrology, Faculty of Pharmacy, University of Porto, Rua de Jorge Viterbo Ferreira, 228, 4050-313 Porto, Portugal

3 Instituto Tecnológico Agrario de Castilla y León, Ctra. de Burgos Km.119, 47071 Valladolid, Spain producer [1]. However, in recent decades, the olive production system has suffered deep changes. In several areas, the traditional olive groves were progressively replaced or converted into new plantations with higher plant intensification or, in some cases, even abandoned. Thus, super-intensive hedgerows or high-density olive groves, with more than one thousand plants per hectare, have emerged, namely in hedgerow regions [2]. Furthermore, alongside improving crop yield, best management practices have been implemented, namely a more efficient use of production factors with increased irrigation, proper fertilization, and better control of pests and diseases [3,4]. Therefore, high-density systems have been adopted due to the easiness of mechanization, high productivity, and lower production costs [5]. Recently, another trend has arisen in traditional producing countries, consisting of the expansion of olive plantation towards nontraditional regions, due to land and water availability. In Spain, this tendency is marked and has led to a successive expansion to coldest areas located in the center and northcentral of the country, like the provinces of Toledo [5] and Valladolid [6]. However, it is known that climatic conditions, 
geographical characteristics, and agricultural practices, have a marked influence on the growth and productivity of the olive tree and so, on the oils' chemical composition, which may even differ between oils produced from olives of the same cultivar but grown in different geographical regions [7]. Nevertheless, to date, most of the studies regarding olive oils obtained from well-known Spanish olive cultivars have been focused on traditional Spanish cultivation regions (e.g., south of Spain) and on a restricted number of cultivars [7].

In this context, Valladolid, a Spanish region located in the north-central of the Iberian Peninsula, has gradually emerged as a new region for olive growing. Thus, a detailed study regarding olive oils extracted from a vast number of cultivars during several crop years would highlight the critical role that this region may have within the Spanish olive and olive oil sector. Therefore, this study intends to evaluate the composition of monovarietal olive oils extracted from 11 olive cultivars (cvs. Arbequina, Arbosana, Arroniz, Cornicabra, Frantoio, Hojiblanca, Manzanilla, Picual, Picudo, Redondilla and Royuela), grown in high-density groves in the province of Valladolid (Spain) during a consecutive 4-year crop season. It is also aimed to verify the possibility of identifying the physicochemical parameters that would possess the most cultivar-discrimination potential for correctly classifying the monovarietal olive oils, independently of the crop year effect on the oils' composition variability.

\section{Materials and methods}

\section{Olive oil samples}

Olive samples were obtained from an experimental highdensity olive grove located in the Medina de Rioseco municipality ( $\left.41^{\circ} 52^{\prime} 48.3^{\prime \prime} \mathrm{N} 5^{\circ} 00^{\prime} 17.9^{\prime \prime} \mathrm{W}\right)$, province of Valladolid (Spain). The olive grove was installed in October 2009, in a plant density of 1666 trees ha $^{-1}$, with a distance per plant of $1.5 \mathrm{~m}$ in the row and 4.0 between rows. Eleven different cultivars were planted, namely: cvs. Arbequina, Arbosana, Arroniz, Cornicabra, Frantoio, Hojiblanca, Manzanilla, Picual, Picudo, Redondilla and Royuela that were growth and the same agronomic and environmental conditions. During four consecutive crop years (2012/2013 to 2015/2016), three independent samples $(\approx 3 \mathrm{~kg}$ each) of each cultivar were hand-picked in late October / early November, when fruit epidermis varied from red spots in less than half (maturation index two) and red or purple in more than half of the olive (maturation index three) [8] and immediately transported to the laboratory of the Agrarian Technological Institute of Castilla y León (ITACyL), Valladolid (Spain). The fruits were extracted in an Abencor pilot extraction plant (Comercial Abengoa S.A., Seville, Spain) that included three main units: a mill, a thermobeater, where the malaxation took place at controlled temperature, and a centrifuge. The olive oils were filtered and stored in the dark in $100 \mathrm{~mL}$ vials at refrigeration conditions until analysis. All the assays were carried out between one and two months after extraction and were made in triplicate. In total, 122 monovarietal olive oils (Arbequina: 12 oils, Arbosana: 12 oils, Arroniz: 12 oils, Cornicabra: 9 oils, Frantoio: 12 oils, Hojiblanca: 12 oils, Manzanilla: 12 oils, Picual: 12 oils, Picudo: 12 oils, Redondilla: 9 oils, and Royuela: 9 oils), were extracted and analyzed.

\section{Physicochemical quality parameters}

All oil samples were analyzed according to the European Union standard methods [9]. Thus, the following physicochemical parameters were assessed: free acidity (FA, in \% of oleic acid), peroxide values ( $\mathrm{PV}$, in $\mathrm{mEqO}_{2} / \mathrm{kg}$ ), as well as the specific extinction coefficients a $232 \mathrm{~nm}$ and $270 \mathrm{~nm}$ $\left(\mathrm{K}_{232}\right.$ and $\mathrm{K}_{270}$, respectively). In addition, trained panelists performed sensory analysis with no defect perceived in any of the oil samples under study. For all oils, a fruity intensity greater than 0 was detected by all panelists according to the European Union standard methods [9].

\section{Total phenols content}

Total phenols content (TPC) was assessed according to the methodology described by Capannesi et al. [10] with the modifications described by Rodrigues et al. [11]. The determination of TPC was performed as follows: $2.5 \mathrm{~g}$ of olive oil were diluted with $2.5 \mathrm{~mL}$ of $n$-hexane $(1: 1 \mathrm{w} / \mathrm{v})$ and extracted three times with methanol/water $(80: 20 ; \mathrm{v} / \mathrm{v})$ under centrifugation ( $5 \mathrm{~min}$ at $5000 \mathrm{rpm}$ ). From the combined extract, $1 \mathrm{~mL}$ was added to $1 \mathrm{~mL}$ of Folin-Ciocalteau reagent and of $\mathrm{Na}_{2} \mathrm{CO}_{3}(7.5 \%)$, to which $7 \mathrm{~mL}$ of distilled water were added. The mixtures were then stored overnight, being the spectrophotometric analysis performed at $765 \mathrm{~nm}$ and the concentration determined using a calibration curve established for caffeic acid in methanol $(0.04-0.18 \mathrm{mg} / \mathrm{mL})$. In accordance, the results were expressed as $\mathrm{mg}$ of caffeic acid equivalents per $\mathrm{kg}$ of olive oil ( $\mathrm{mg} \mathrm{CAE} / \mathrm{kg}$ ).

\section{Oxidative stability (Rancimat)}

The oxidative stability (OS) was determined by measuring the oxidation induction time on a Rancimat 743 apparatus (Metrohm CH, Switzerland). $3.00 \mathrm{~g}$ of olive oil were heated at $120.0 \pm 1.6{ }^{\circ} \mathrm{C}$ under an air flow rate of $20 \mathrm{~L} / \mathrm{h}$ (filtered, cleaned, and dried). The resulting volatile compounds were collected in water, and the increasing of water conductivity $(\mathrm{mS} / \mathrm{cm})$ was continuously measured. The time (in hours) taken to reach the conductivity inflection curve point was recorded and corresponded to the OS value. 


\section{Fatty acids composition}

Fatty acids were assessed as their methyl esters after cold alkaline transesterification with methanolic potassium hydroxide solution [9] and extraction with n-heptane. The fatty acid profile was determined using a Chrompack CP 9001 chromatograph equipped with a split-splitless injector, a flame ionization detector (FID), an autosampler Chrompack CP-9050 and a fused silica capillary column (CP-Sil88, $50 \mathrm{~m} \times 0.25 \mathrm{~mm}$ i.d.; Varian, Palo Alto, CA, USA). Helium was used as carrier gas at an internal pressure of $110 \mathrm{kPa}$. The temperatures of the detector and injector were 250 and $230{ }^{\circ} \mathrm{C}$, respectively. The split ratio was 1:50, and the injected volume was of $1 \mu \mathrm{L}$. The results are expressed in relative percentage of each fatty acid, calculated by internal normalization of the chromatographic peak area eluting between myristic and lignoceric methyl esters. A control sample (olive oil 47,118, Supelco) and a fatty acids methyl esters standard mixture (Supelco 37 FAME Mix) were used for identification and calibration purposes (Sigma, Spain).

\section{Tocopherols composition}

Tocopherols were evaluated following the international standard ISO 9936 [9], with some modifications as described by Rodrigues et al. [6]. Tocopherols standards ( $\alpha, \beta, \gamma$, and $\delta)$ were purchased from Sigma (Spain), and 2-methyl2-(4,8,12-trimethyltridecyl) chroman-6-ol (tocol), used as the internal standard, was from Matreya Inc. (Pleasant Gap, PA, USA). Filtered olive oil (50 mg) plus $10 \mu \mathrm{L}$ of the internal standard solution (tocol, $100 \mu \mathrm{g} / \mathrm{mL}$ prepared with $\mathrm{n}$-hexane) were mixed and then centrifuged for $5 \mathrm{~min}$ at $13,000 \mathrm{rpm}$, being the obtained supernatant was analyzed by high-performance liquid chromatography (HPLC). The liquid chromatograph consisted of a Jasco integrated system (Japan) equipped with a LC-NetII/ADC data unit, a PU-1580 Intelligent Pump, and a FP-920 fluorescence detector $\left(\lambda_{\text {excitation }}=290 \mathrm{~nm}\right.$ and $\left.\lambda_{\text {emission }}=330 \mathrm{~nm}\right)$. The chromatographic separation was achieved on a Luna Silica column ( $3 \mu \mathrm{m}, 100 \times 3.0 \mathrm{~mm}$ from Phenomenex, USA), operating at constant room temperature $\left(23^{\circ} \mathrm{C}\right)$. The eluent was a mixture of $\mathrm{n}$-hexane and 1,4-dioxane $(97.5: 2.5)$ at a $0.7 \mathrm{~mL} / \mathrm{min}$ flow rate. Data were analyzed with the ChromNAV Control Center-JASCO Chromatography Data Station (Japan). The compounds were identified by chromatographic comparisons with standards, by co-elution, and by the evaluation of the UV spectra. Quantification was based on the internal standard method, using the fluorescence signal response and individual calibration curves for each tocopherol. Total vita$\min \mathrm{E}$ was quantified as the sum of the individual tocopherol contents.

\section{Statistical analysis}

One-way ANOVA followed by the Tukey's post-hoc multicomparison test, when a statistically significant cultivar effect was found on the physicochemical parameters evaluated, was applied. Boxplots were also used to visualize the experimental data, being plotted the 1st, 2nd (median), and 3rd quartiles, as well as the box bars, which represented the values comprised between the 1 st and 3rd quartiles. In addition, whiskers were plotted $(1.5 \times$ the inner quartile spread in length, being measured from the median), allowing establishing an arbitrary cutoff point and to identify possible outside values. Minimum and maximum values that fell outside the whisker range are also plotted (dot symbols) and symbolized possible extreme values or outliers. Linear discriminant analysis (LDA) was applied as a supervised classification technique to evaluate the possibility of the studied parameters to correctly identify the monovarietal olive oils according to the olive cultivar. The LDA was coupled with the simulated annealing (SA) algorithm to selected the non-redundant parameters with the most discriminant potential for recognizing the oils' cultivar among the oils' experimental data collected during the four consecutive crop years (i.e., FA; PV; $K_{232} ; K_{270}$; TPC; OS; 12 fatty acids; and $\alpha-, \beta$ - and $\gamma$-tocopherol) as well as to minimize noise effects $[13,14]$. The predictive performance of the LDA-SA model was assessed based on the leave-one-out cross-validation (LOO-CV) and the repeated K-fold-CV (with 10 repeats and $\mathrm{K}$ set equal to 4 , allowing that $25 \%$ of the data were used for validation purposes at each iteration). The percentage of correct classifications (i.e., the model's sensitivity) was calculated for both variants. 3D plot of the three main discriminant functions was used, being the class membership ellipses established using the posterior probabilities, computed using the Bayes' theorem [15]. The statistical analysis was performed using the Subselect [14] and MASS [16] packages of the open-source statistical program $\mathrm{R}$ (version 2.15.1), at a 5\% significance level.

\section{Results and discussions}

\section{Quality parameters}

To establish the quality grade of the oils obtained during the four consecutive crop years (2012/2013 to 2015/2016), from the eleven cultivars under study, several parameters were determined, including the FA, the PV, and the extinction coefficient at 232 and $270 \mathrm{~nm}\left(K_{232}\right.$ and $\left.K_{270}\right)$. Table 1 shows, for each parameter, the mean values ( \pm standard deviation) of the monovarietal oils obtained. These results, together with the fact that no defect was perceived and fruity intensity was detected by trained panelists, all oils could be classified 


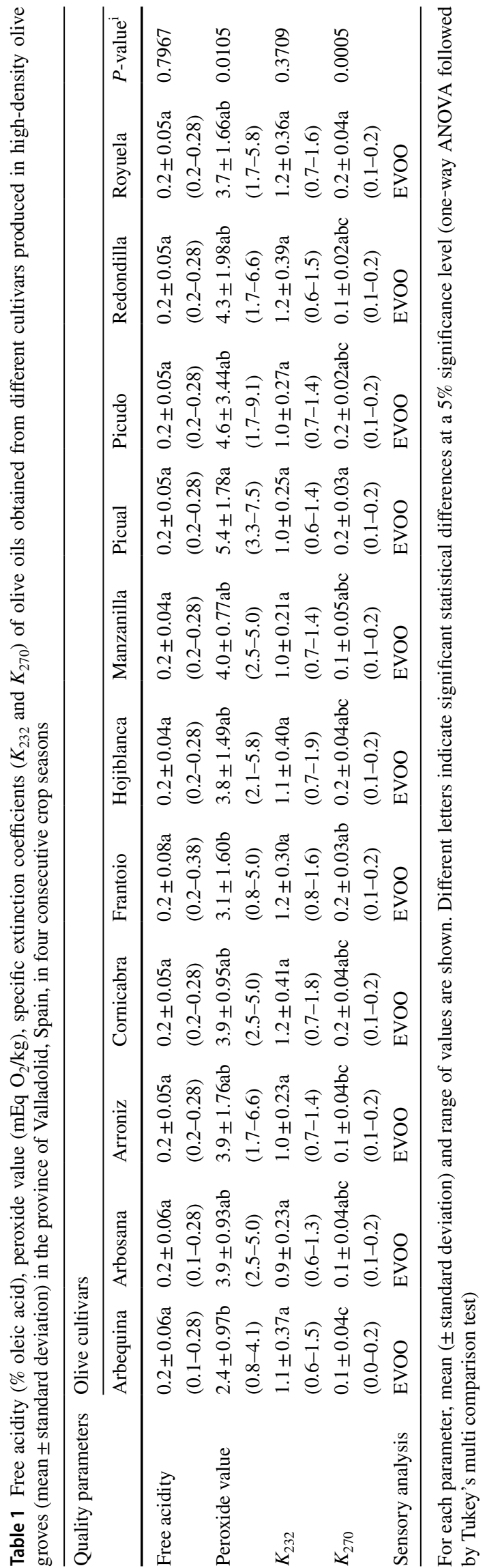

as Extra Virgin Olive Oil (EVOO) [9]. Also, it was found that the FA was not significantly different $(P$-value $=0.7967$, one-way ANOVA) among the evaluated oils (varying from 0.2 to $0.3 \%$ ). This finding is in line with the results reported in the literature for oils extracted from olives collected in high-density olive groves $[6,7,17]$. Also, no statistically significant cultivar effect was observed for the $K_{232}$ (ranging between 0.92 and $1.24 ; P$-value $=0.3709$, one-way ANOVA). Oppositely, PV and $K_{270}$ were significantly influenced by the olive cultivar (ranging from 2.4 to $5.4 \mathrm{mEq} \mathrm{O} \mathrm{O}_{2} /$ $\mathrm{kg}$ and $0.12-0.18$, respectively; $P$-value $\leq 0.0105$, one-way ANOVA). Arbequina oils had the lowest PV and $K_{270}$ mean values, and Picual oils showed the highest ones, in agreement with the values reported for these cultivars in Galicia (Spain) [17]. For the extinction coefficients the results are also in accordance with those previously reported by Mansouri et al. [18] for olive oils from three European cultivars planted in high-density groves in eastern Morocco as well as by Farinelli and Tombesi [19] for Arbequina and other four Italian olive cultivars grown in high-density hedges planted in central Italy.

\section{Total phenolic contents and oxidative stability}

The TPC and OS of the eleven monovarietal oils produced during the four consecutive crop years are shown in Fig. 1. For TPC, a significant cultivar effect was observed ( $P$-value $<0.0001$, one-way ANOVA), being found that the cultivar that stood out with the highest TPC was $c v$. Picudo (mean value of $215.3 \mathrm{mg} \mathrm{CAE} / \mathrm{kg}$ ) and cv. Redondilla with the lowest levels (mean value of $109.0 \mathrm{mg} \mathrm{CAE} / \mathrm{kg}$ ). The results obtained are in line with those previously reported by Rodrigues el al. [11], for olive oils extracted from olives harvested from centennial trees located in the northeast of Portugal. Regarding the OS, which allows estimating of the oils susceptibility to oxidative degradation [20], the olive cultivar had a significant effect $(P$-value $<0.0001$ one-way ANOVA), as can be inferred from Fig. 1. The highest value was found for cv. Cornicabra oils (mean value of $24.4 \mathrm{~h}$ ) and the lowest one for $\mathrm{cv}$. Redondilla oils (mean value of $10.6 \mathrm{~h}$ ). It should be noticed that all OS determined were greater than the values reported by Ceci et al. [21] for Argentinian oils obtained with the same olive cultivars, highlighting the well-documented influence of the geographical origin and the edaphoclimatic conditions on the oils' chemical composition.

\section{Fatty acids composition}

Twenty-two fatty acids (six saturated, four monounsaturated, and two polyunsaturated fatty acids, i.e., SFA, MUFA, and PUFA, respectively) were detected in the studied eleven monovarietal olive oils, extracted during 

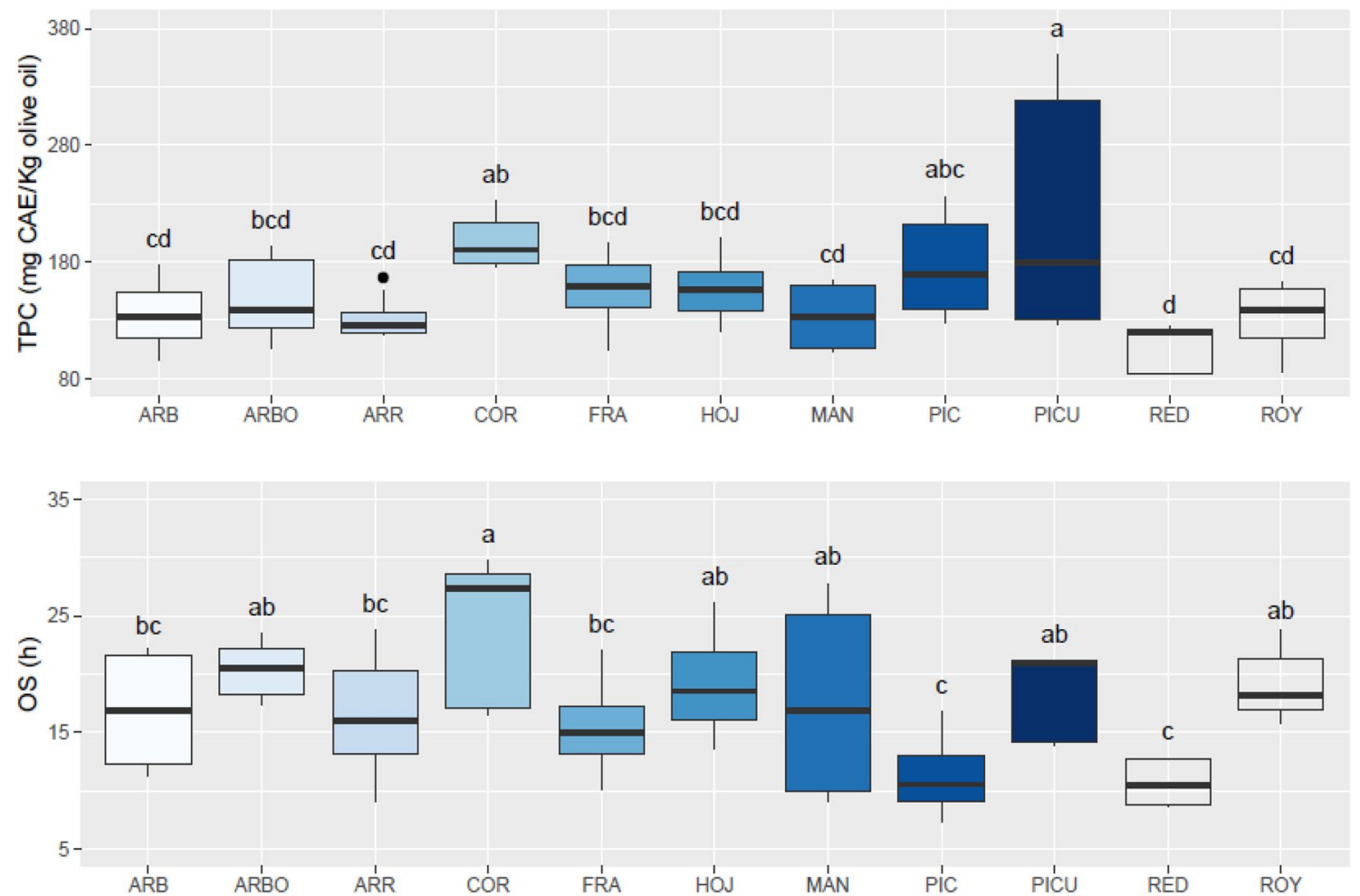

Fig. 1 Boxplot of the total phenols (TPC) (mg CAE/kg of olive oil) and oxidative stability (OS, hours) of olive oils obtained from different cultivars produced in high-density olive groves (mean \pm standard deviation) in the province of Valladolid, Spain, in four consecutive crop seasons. Different lowercase letters indicate significant statisti- cal differences at a 5\% significance level (one-way ANOVA followed by Tukey's multicomparison test). ARB cv. Arbequina, ARBO cv. Arbosana, ARR cv. Arroniz, COR cv. Cornicabra, FRA $c v$. Frantoio, HOJ $c v$. Hojiblanca, MAN $c v$. Manzanilla, PIC cv. Picual, PICU $c v$. Picudo, RED $c v$. Redondilla, ROY $c v$. Royuela the four crop seasons, being the mean relative abundances listed in Table 2. As can be inferred, the olive cultivar had a significant statistical effect on the fatty acids relative abundance $(P$-value $<0.0001$, one-way ANOVA), except arachidic acid $\left(\mathrm{C}_{20: 0}\right)$, lignoceric acid $\left(\mathrm{C}_{24: 0}\right)$ and gadoleic acid $\left(\mathrm{C}_{20: 1}\right)(P$-value $\geq 0.0574$, one-way ANOVA). Globally, the most abundant was, as expected, oleic acid $\left(\mathrm{C}_{18: 1}\right)$, followed by palmitic acid $\left(\mathrm{C}_{16: 0}\right)$, linoleic acid $\left(\mathrm{C}_{18: 2}\right)$, stearic acid $\left(\mathrm{C}_{18: 0}\right)$, and linolenic acid $\left(\mathrm{C}_{18: 3}\right)$. According to the literature and standard regulations, these previous five fatty acids are the most abundant ones in olive oils $[6,18$, 19, 22-24]. Olive oils from cv. Redondilla had the lowest oleic acid (mean abundance of $76.9 \%$ ) and those from cv. Manzanilla showed the highest levels (mean abundance of $82.5 \%)$. These fatty acid relative abundances are similar to those found by Rodrigues et al. [6] but, in general, higher compared to the data reported by Farinelli and Tombesi [19] and Mansouri et al. [18] for oils produced in highdensity olive groves or, more recently, by Gila et al. [24] for cv. Arbequina and Picual oils. Regarding palmitic acid, the second most abundant fatty acid, oils from cv. Hojiblanca had the lowest amounts (mean abundance of 9.1\%) and cv. Redondilla oils had the highest ones (mean abundance of $10.9 \%$ ). Similar relative abundances have been described in the literature for oils obtained from different olive cultivars $[6,23,25]$. Regarding the total abundances of the SFA, MUFA, and PUFA, the values are shown in Fig. 2, being clear the significant effect of the olive culti$\operatorname{var}(P$-value $<0.0001$, one-way ANOVA $)$. The total SFA abundances varied from 11.8 (cv. Arroniz) to $13.5 \%$ (cv. Picual). The values are globally lower than those previously reported for oils produced in high-density olive groves $[18,19]$. On the other hand, oils from cv. Redondilla had the lowest levels of MUFA (78.2\%) and those from cv. Manzanilla showed the highest amounts (83.6\%), which are, in general, greater than those reported in the literature [26, 27]. Finally, PUFA were less abundant in oils from cv. Manzanilla (4.0\%) and the highest levels were found for cv. Redondilla oils (8.3\%). These results are in accordance with those found by Farinelli and Tombesi [19] for Italian oils produced in high-density olive groves and by Rodrigues et al. [6] for cv. Arbequina oils obtained from when different planting densities were studied. 


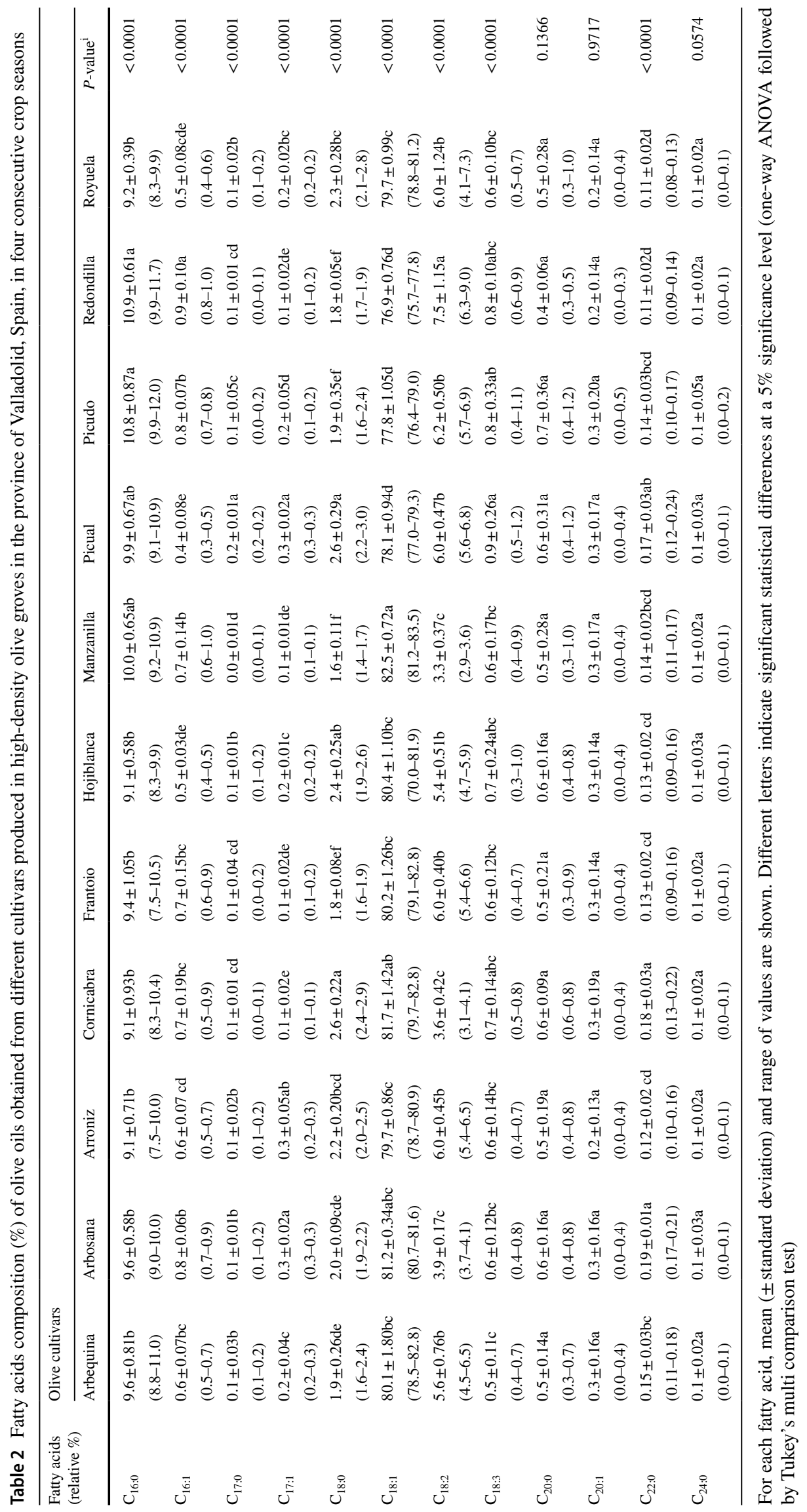



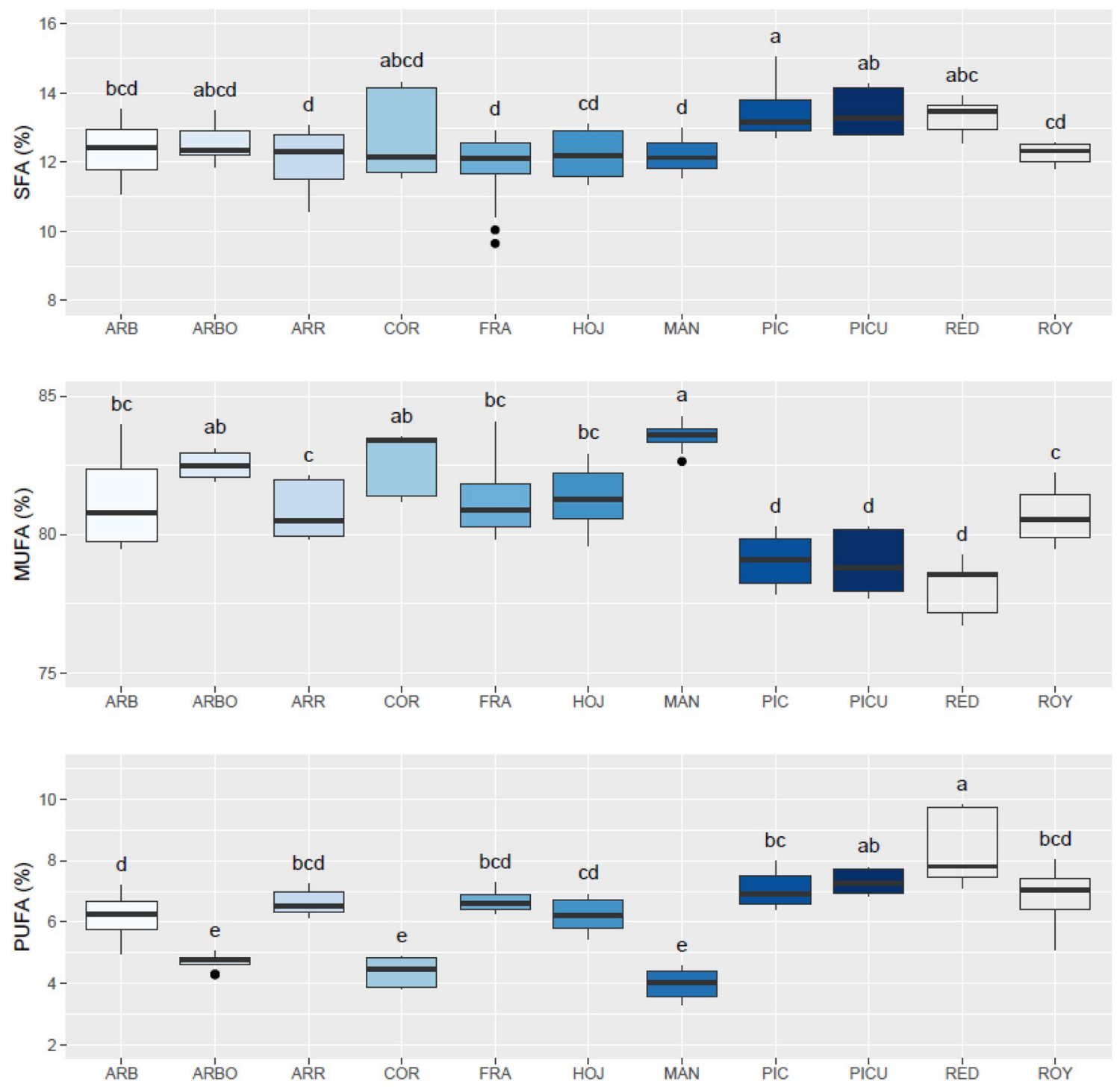

Fig. 2 Boxplots of the contents (\%) of SFA, MUFA, and PUFA of olive oils obtained from different cultivars produced in high-density olive groves (mean \pm standard deviation) in the province of Valladolid, Spain, in four consecutive crop seasons. Different lowercase letters mean significant statistical differences at a 5\% significance level

\section{Tocopherols composition}

Three tocopherols were detected in all the monovarietal oils studied ( $\alpha$-, $\beta$ - and $\gamma$-tocopherol), which contents were significantly different according to the olive cultivar, as shown in Fig. 3 ( $P$-value $\leq 0.0006$, one-way ANOVA). Among them, $\alpha$-tocopherol was the predominant vitamin E compound (mean content from 160.9 to $279.8 \mathrm{mg} / \mathrm{kg}$ for cvs. Royuela and Arbosana, respectively). Similar $\alpha$-tocopherol content ranges (varying from 131.5 to $269.9 \mathrm{mg} / \mathrm{kg}$ ) were reported by López-Cortés et al. [23] for traditional varietal oils (cvs. Alfafara, Farga, Morruda, and Picual) grown in eastern Spain or by Gila et al. [24] for cvs. Arbequina and (one-way ANOVA followed by the Tukey's multicomparison test). $A R B c v$. Arbequina, $A R B O c v$. Arbosana, ARR $c v$. Arroniz, COR $c v$. Cornicabra, FRA $c v$. Frantoio, HOJ $c v$. Hojiblanca, MAN $c v$. Manzanilla, PIC $c v$. Picual, PICU $c v$. Picudo, RED $c v$. Redondilla, ROY $c v$. Royuela

Picual oils (289.2 and $283.3 \mathrm{mg} / \mathrm{kg}$, respectively). Regarding $\beta$ - and $\gamma$-tocopherols, smaller quantities (mean contents equal or lower than $2.6 \mathrm{mg} / \mathrm{kg}$ (cv. Manzanilla) or $15.5 \mathrm{mg} /$ $\mathrm{kg}$ (cv. Picual), respectively) were found, which are, in general, in-line with the literature data [7, 17, 24]. Since $\alpha$-tocopherol represented $90-95 \%$ of the total content of tocopherols, a similar trend (Fig. 2) was observed for total vitamin $\mathrm{E}$ amounts, which is here presented as the sum of all tocopherols. In this sense, cv. Arbosana oils had the highest mean content $(286.9 \mathrm{mg} / \mathrm{kg})$ while cvs. Redondilla and Royuella had the lowest amount $(175.9 \mathrm{mg} / \mathrm{kg})$. It is known that a higher content of vitamin $\mathrm{E}$ corresponds to greater resistance to oxidation [28]. Nevertheless, other factors must 
Fig. 3 Boxplots of the contents $\left(\mathrm{mg} / \mathrm{kg}\right.$ of olive oil) of $\alpha^{-}, \beta^{-}$, and $\gamma$-tocopherols as well as of vitamin $\mathrm{E}$ (total tocopherol content) of olive oils obtained from different cultivars produced in high-density olive groves (mean \pm standard deviation) in the province of Valladolid, Spain, in four consecutive crop seasons. Different lowercase letters mean significant statistical differences at a $5 \%$ significance level (one-way ANOVA followed by the Tukey's multicomparison test). $A R B C v$. Arbequina, $A R B O c v$. Arbosana, $A R R c v$. Arroniz, COR cv. Cornicabra, FRA cv. Frantoio, HOJ $c v$. Hojiblanca, MAN $c v$. Manzanilla, PIC cv. Picual, PICU $c v$. Picudo, RED $c v$. Redondilla, $R O Y c v$. Royuela
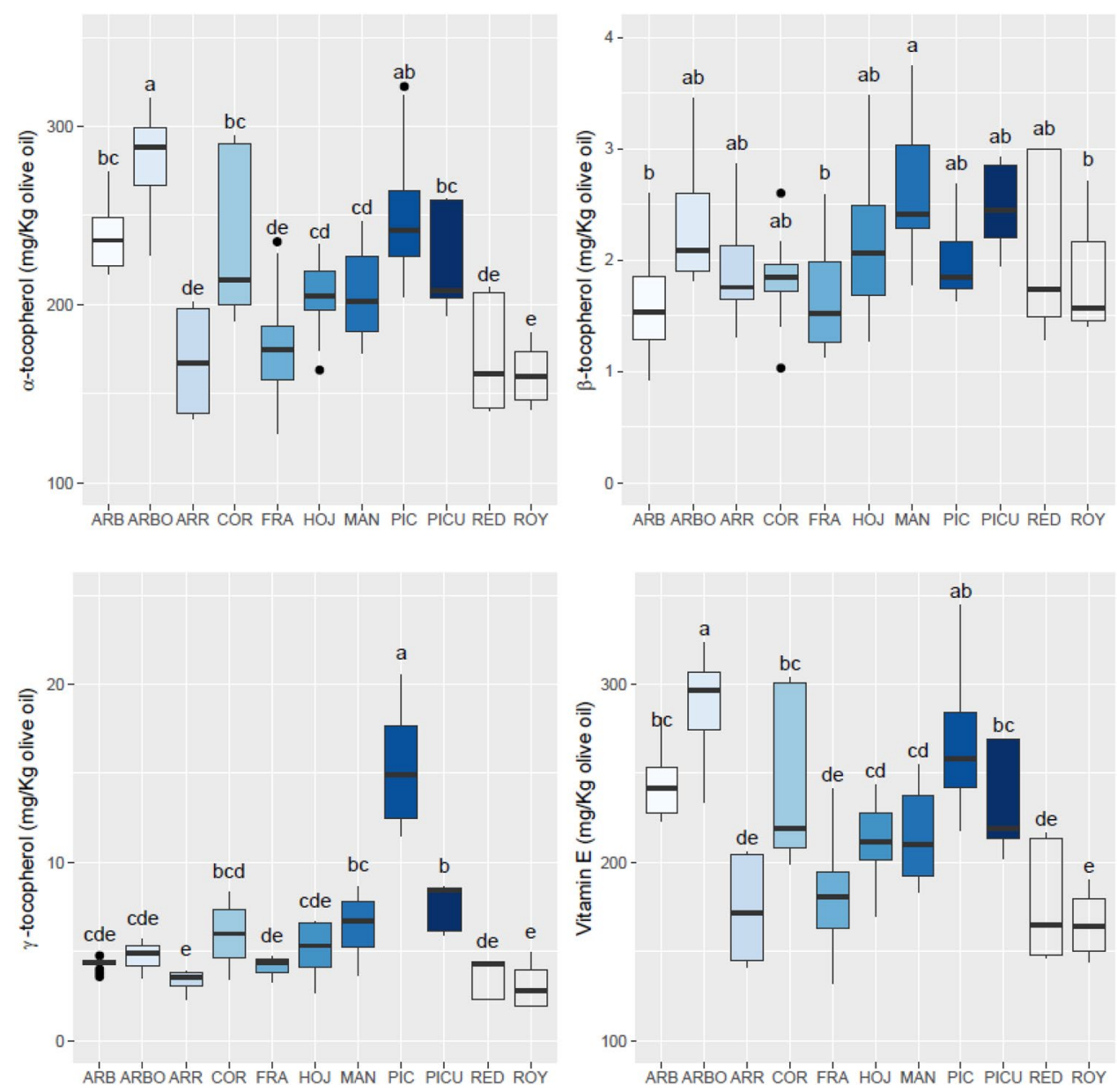

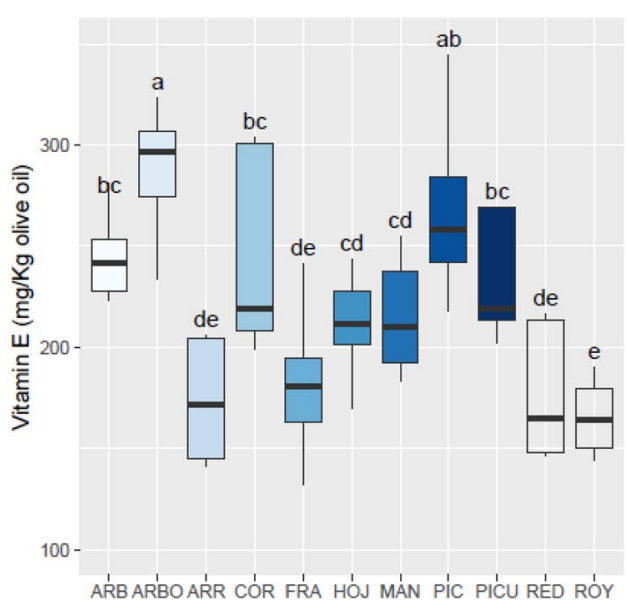

be considered to have a preponderant effect on the OS, like phenolics and fatty acid composition. The fatty acid composition was the reason that two cultivars with similar amounts of tocopherols (cvs. Redondilla and Royuella) showed significant differences in OS. Redondilla with the highest quantity of PUFA presents the lowest OS values and, in opposite, cv. Royuella possesses the lowest PUFA and high OS. Tocopherols are also important to the nutritional value of olive oil. Olive oils of cv. Arbosana together with cvs. Picual and Cornicabra, due to their high amount of tocopherols, display a high nutritional value, and their consumption would lead to better health benefits.

\section{Monovarietal oils discrimination based on the quality-chemical profiles}

The studied monovarietal olive oils were produced during four consecutive crop years from olives collected from eleven cultivars grown in the same olive grove (same geographical region). Although the known effect of the climatic conditions varied along the four crop years, it was possible to find a significant statistical impact in most of the chemical parameters evaluated. Thus, it was further assessed the possibility of using the established quality-chemical profiles to discriminate the monovarietal oils under study, using an LDA. Furthermore, to identify the non-redundant parameters with the most olive cultivar discriminant power, among 21 of the 25 parameters evaluated (being not included vitamin E, SFA, MUFA and PUFA, in order to minimize the risk of selecting correlated variables), the SA algorithm was implemented. The multivariate classification approach allowed establishing a LDA-SA model based on 15 parameters (FA, PV, $K_{270}$, TPC, OS, $\alpha$-tocopherol, $\beta$-tocopherol, $\gamma$-tocopherol, $\mathrm{C}_{16: 1}, \mathrm{C}_{17: 1}, \mathrm{C}_{18: 2}, \mathrm{C}_{18: 3}, \mathrm{C}_{20: 1}, \mathrm{C}_{22: 0}$, and $\mathrm{C}_{24: 0}$ ), which three first discriminant functions explained $86.5 \%$ of the data variability. It should be noticed that among the 15 selected parameters not all were significant (e.g., FA, $\mathrm{C}_{20: 1}$ and $\mathrm{C}_{24: 0}$; as shown in Tables 1,2). The inclusion of these variables on the classification model can be tentatively explained since, as discussed by Lo et al. [29], variables with strong prediction power sometimes fail to be significant since the statistical techniques used in each case depend on different properties of the underlying distributions. The established LDA-SA model correctly identified the oils' olive cultivar of $96.7 \%$ of the original grouped samples (one cv. Arroniz oil and one cv. Hojiblanca oil missclassified as 


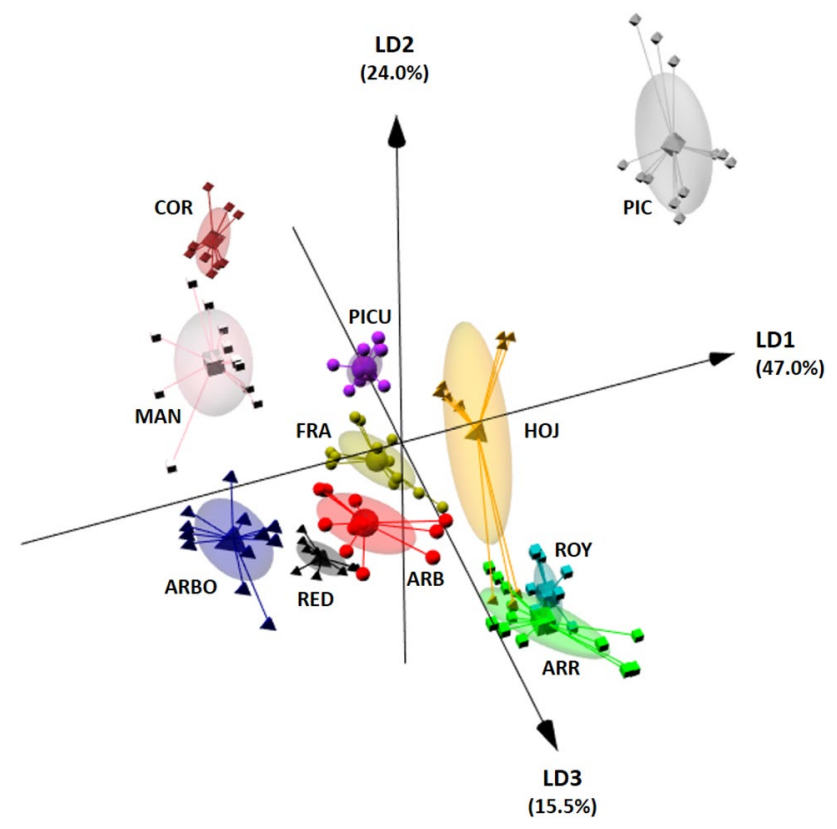

Fig. 4 3D-plot regarding the discrimination of monovarietal olive oils obtained from different cultivars $(A R B c v$. Arbequina, $A R B O c v$. Arbosana, ARR $c v$. Arroniz, COR $c v$. Cornicabra, FRA $c v$. Frantoio, $H O J c v$. Hojiblanca, MAN $c v$. Manzanilla, PIC $c v$. Picual, PICU $c v$. Picudo, RED $c v$. Redondilla, $R O Y c v$. Royuela) produced in high density-olive groves in the province of Valladolid, Spain, in four consecutive crop seasons., using a LDA-SA model established using 15 nonredundant selected parameters (FA, PV, $K_{270}$, TPC, OS, $\alpha$-tocopherol, $\beta$-tocopherol, $\gamma$-tocopherol, $\mathrm{C}_{16: 1}, \mathrm{C}_{17: 1}, \mathrm{C}_{18: 2}, \mathrm{C}_{18: 3}, \mathrm{C}_{20: 1}, \mathrm{C}_{22: 0}$, and $\mathrm{C}_{24: 0}$ ) from a dataset comprising 21 independent chemical variables

cv. Royuela oil, Fig. 4) and $93.5 \%$ of the samples for the LOO-CV procedure (four cv. Arroniz oils and one cv. Hojiblanca oil missclassified as cv. Royuela oil; one cv. Royuela oil misclassified as cv. Hojiblanca oil). Therefore, it could be inferred that the studied olive oils possessed a cultivardependent chemical composition that allowed the oils discrimination independently of the possible crop-year effect. The developed classification model was only less powerful for cv. Arroniz oils' identification. This finding is of utmost relevance when a cultivar genuineness assessment is envisaged for high-value monovarietal EVOO commercial classification.

The satisfactory predicted performance was further checked using the repeated K-fold-CV procedure, which enabled to retain $25 \%$ of the dataset for validation purposes. The repeated K-fold-CV ( 10 repeats $\times 4$ folds) showed a mean sensitivity (i.e., correct classification percentage) of $92 \pm 5 \%$ (varying from 81 to $100 \%$ ). The satisfactory performance of the proposed classification multivariate approach is in line with the results previously reported in the literature, although, in general, for a lower number of cultivars and crop years. For example, Olmo-García et al. [30] also achieved a successful olive oil discrimination according to the cultivar using a partial least square discriminant analysis (PLS-DA) to differentiate oils produced in the USA in a single crop year, from eight different cultivars, based on phenolic and triterpenic compounds, tocopherols, sterols, and free fatty acids. Maléchaux et al. [31] described similar satisfactory classification performances for discriminating monovarietal olive oils produced from six French cultivars grown over three harvest years (2016, 2017, and 2018), using PLS-DA based on near-infrared and mid-infrared spectroscopic data used alone or combined. More recently, Özdikicierler [32] also reported the successful discrimination of oils obtained from eight olive cultivars from four different regions of Turkey using PLS-DA based on fatty acid and sterol composition.

\section{Conclusions}

The carried out study focused on monovarietal olive oils produced in a high-density grove located in the Spanish region of Valladolid, a non-traditional olive oil producing region, characterized by its slight continental climate, with moderately cold winters and hot, sunny summers, but with cool nights, with not abundant precipitation. The results pointed out that the oils produced from the 11 studied cultivars (cvs. Arbequina, Arbosana, Arroniz, Cornicabra, Frantoio, Hojiblanca, Manzanilla, Picual, Picudo, Redondilla, and Royuela) during four consecutive crop years could be classified as extra virgin olive oils and so, possessed a similar quality grade as those usually produced in more traditional Mediterranean regions. As for the traditional cultivation geographical regions, the olive cultivar had a marked effect on the chemical composition of olive oils, mainly in monounsaturated fatty acids. Indeed, the oils' fatty acids composition stands out from oils also produced from the same cultivars but originated from more traditional olive tree cultivation areas of Spain and the world. This study also found that, despite the different cultivation years evaluated, the chemical quality profiles could be used to successfully discriminate the monovarietal oils under study, being possible to use this chemical information as putative cultivar genuineness biomarkers. Finally, the study highlighted the possibility of obtaining olive oils with superior quality in a cold non-traditional geographical region and strengthening the Valladolid region as a potential and emerging geographical area for olive oil production.

Acknowledgements The authors are grateful to the Foundation for Science and Technology (FCT, Portugal) for financial support by national funds FCT/MCTES to CIMO (UIDB/00690/2020) and Associate Laboratories for Green Chemistry-LAQV (UIDB/50006/2020) and SusTEC (LA/P/0007/2020). Nuno Rodrigues thanks to National funding by FCT- Foundation for Science and Technology, P.I., through the institutional scientific employment program-contract. 


\section{Declarations}

Conflict of interest The authors declare that they have no conflict of interest.

Compliance with ethics requirements This study does not contain any studies with human participants or animals performed by any of the authors.

\section{References}

1. Rallo L, DíeZ CM, Morales-Sillero A, Miho H, Priego-Capote F, Rallo P (2018) Quality of olives: a focus on agricultural preharvest factors. Sci Hortic 233:491-509

2. Banco A, Trentacoste E, Monasterio RP (2021) Characterization of virgin olive oils from Spanish olive varieties introduced in Mendoza, Argentina, and their comparison with the autochthonous variety. J Sci Food Agric 101:518-524

3. Romero-Gámez M, Castro-Rodríguez J, Suárez-Rey EM (2017) Optimization of olive growing practices in Spain from a life cycle assessment perspective. J Clean Prod 149:25-37

4. Colombo S, Sánchez-Martínez JD, Perujo-Villanueva M (2020) The trade-offs between economic efficiency and job creation in olive grove smallholdings. Land Use Policy 96:104696

5. Gómez-del-Campo M, Trentacoste ER, Connor DJ (2020) Longterm effects of row spacing on radiation interception, fruit characteristics and production of hedgerow olive orchards (cv. Arbequina). Sci Hortic 272:109583

6. Rodrigues N, Casal S, Peres AM, Baptista P, Bento A, Martíne H, Asensio-S.-Manzanera MC, Pereira JA (2018) Effect of olive trees density on the quality and composition of olive oil from $\mathrm{cv}$. Arbequina. Sci Hortic 238:222-233

7. Borges TH, Pereira JA, Cabrera-Vique C, Lara L, Oliveira AF, Seiquer I (2017) Characterization of Arbequina virgin olive oils produced in different regions of Brazil and Spain: physicochemical properties, oxidative stability and fatty acid profile. Food Chem 215:454-462

8. Hermoso M, Uceda M, García A, Morales B, Frias ML, Fernandez A (1991) Elaboración de 505 Aceite de Calidad. Cons Agric y Pesca, Ser Apunt 5:173

9. Regulation C (1991) (ECC) n॰ 2568/91: on the characteristics of olive oil and olive-pomace oil and on the relevant methods of analysis. Off J Eur Union L248:1-82

10. Capannesi C, Palchetti I, Mascini M (2000) Electrochemical sensor and biosensor for polyphenols detection in olive oils. Food Chem 71:553-562

11. Rodrigues N, Casal S, Peres AM, Baptista P, Pereira JA (2020) Seeking for sensory differentiated olive oils? The urge to preserve old autochthonous olive cultivars. Food Res Int 128:108759

12. ISO 9936 (2006) Animal and vegetable fats and oils-determination of tocopherol and tocotrienol contents by high-performance liquid chromatography

13. Bertsimas D, Tsitsiklis J (1993) Simulated annealing. Stat Sci $8: 10-15$

14. Cadima J, Cerdeira JO, Minhoto M (2004) Computational aspects of algorithms for variable selection in the context of principal components. Comput Stat Data Anal 47:225-236

15. Bishop CM (2006) Pattern recognition and machine learning, 1st edn. Springer, New York

16. Venables WN, Ripley BD (2002) Modern applied statistics with $\mathrm{S}$ (Statistics and Computing), 4th edn. Springer, New York

17. Reboredo-Rodríguez P, González-Barreiro C, Cancho-Grande B, Fregapane G, Salvador MD, Simal-Gándara J (2015) Characterisation of extra virgin olive oils from Galician autochthonous varieties and their co-crushings with Arbequina and Picual cv. Food Chem 176:493-503

18. Mansouri F, Ben Moumen A, Aazza S, Belha K, Fauconnier ML, Sindic M, Serghini Caid H, Elamrani A (2019) Quality and chemical profiles of virgin olive oils of three European cultivars suitable for super-high-density planting conditions in eastern Morocco. Mater Today 13:998-1007

19. Farinelli D, Tombesi S (2015) Performance and oil quality of 'Arbequina' and four Italian olive cultivars under super high density hedgerow planting system cultivated in central Italy. Sci Hortic 192:97-107

20. Andreou V, Dimopoulos G, Alexandrakis Z, Katsaros G, Oikonomou D, Toepfl S, Heinz V, Taoukis P (2017) Shelf-life evaluation of virgin olive oil extracted from olives subjected to nonthermal pretreatments for yield increase. Innov Food Sci Emerg Technol 40:52-57

21. Ceci LN, Mattar SB, Carelli AA (2017) Chemical quality and oxidative stability of extra virgin olive oils from San Juan province (Argentina). Food Res Int 100:764-770

22. Laincer L, Laccarino L, Amato J, Pagano B, Pagano A, Tenore G, Tamendjari A, Rovellini P, Venturini S, Bellan G, Ritieni A, Mannina L, Novellino E, Randazzo A (2016) Characterization of monovarietal extra virgin olive oils from the province of Béjaïa (Algeria). Food Res Int 89:1123-1133

23. López-Cortés I, Salazar-García DC, Velázquez-Martí B, Salazar DM (2013) Chemical characterization of traditional varietal olive oils in East of Spain. Food Res Int 54:1934-1940

24. Gila A, Sánchez-Ortiz A, Jiménez A, Beltrán G (2021) The ultrasound application does not affect to the thermal properties and chemical composition of virgin olive oils. Ultrason Sonochem 70:105320

25. Xiang C, Xu Z, Liu J, Li T, Yang Z, Ding C (2017) Quality, composition, and antioxidant activity of virgin olive oil from introduced varieties at Liangshan. LWT 78:226-234

26. Alowaiesh B, Singh Z, Fang Z, Kailis SG (2018) Harvest time impacts the fatty acid compositions, phenolic compounds and sensory attributes of Frantoio and Manzanilla olive oil. Sci Hortic 14:74-80

27. Kong W, Han R, Liu N, Bai W, Ma J, Bai X, Liang J, Wang J, Zhang J (2019) Dynamic assessment of the fruit quality of olives cultivated in Longnan (China) during ripening. Sci Hortic 253:8-16

28. Rodrigues N, Casal S, Cruz R, Peres AM, Baptista P, Pereira JA (2020) GxE effects on tocopherol composition of oils from very old and genetically diverse olive trees. J Am Oil Chem Soc 97:497-507

29. Lo A, Chernoff H, Zheng T, Lo S-H (2015) Why significant variables aren't automatically good predictors. Proc Natl Acad Sci USA 112:13892-13897

30. Olmo-García L, Polari JJ, Li X, Bajoub A, Fernández-Gutiérrez A, Wang SC, Carrasco-Pancorbo A (2019) Study of the minor fraction of virgin olive oil by a multi-class GC-MS approach: comprehensive quantitative characterization and varietal discrimination potential. Food Res Int 125:108649

31. Maléchaux A, Le Dréau Y, Artaud J, Dupuy N (2020) Control chart and data fusion for varietal origin discrimination: application to olive oil. Talanta 217:121115

32. Özdikicierler O (2021) Chemometric discrimination of Turkish olive oils by variety and region using PCA and comparison of classification viability of SIMCA and PLS-DA. Eur Food Res Technol 247:157-168

Publisher's Note Springer Nature remains neutral with regard to jurisdictional claims in published maps and institutional affiliations. 